\title{
Quinolone prophylaxis for the prevention of BK virus infection in kidney transplantation: study protocol for a randomized controlled trial
}

Atul Humar ${ }^{1 \dagger}$, John Gill ${ }^{2 \dagger}$, Olwyn Johnston ${ }^{3}$, Dean Fergusson ${ }^{4}$, Andrew A House ${ }^{5}$, Louise Lebel ${ }^{6}$, Sandra Cockfield ${ }^{1}$, S Joseph Kim ${ }^{7}$, Jeff Zaltzman ${ }^{8}$, Marcelo Cantarovich ${ }^{9}$, Martin Karpinski ${ }^{10}$, Tim Ramsay ${ }^{6}$ and Greg A Knoll ${ }^{11^{*}}$

\begin{abstract}
Background: BK virus infection has emerged as a major complication in kidney transplantation leading to a significant reduction in graft survival. There are currently no proven strategies to prevent or treat BK virus infection. Quinolone antibiotics, such as levofloxacin, have demonstrated activity against BK virus. We hypothesize that administration of a quinolone antibiotic, when given early post-transplantation, will prevent the establishment of BK viral replication in the urine and thus prevent systemic BK virus infection.

Methods/design: The aim of this pilot trial is to assess the efficacy, safety and feasibility of a 3-month course of levofloxacin in the kidney transplant population. This is a multicenter, randomized, double-blind,

placebo-controlled trial with two parallel arms conducted in 11 Canadian kidney transplant centers. A total of 154 patients with end-stage renal disease undergoing kidney transplantation will be randomized to receive a 3-month course of levofloxacin or placebo starting in the early post-transplant period. Levofloxacin will be administered at $500 \mathrm{mg}$ po daily with dose adjustments based on kidney function. The primary outcome will be the time to occurrence of BK viruria within the first year post-transplantation. Secondary outcomes include BK viremia, measures of safety (adverse events, resistant infections,Clostridium difficile-associated diarrhea), measures of feasibility (proportion of transplanted patients recruited into the trial), proportion of patients adherent to the protocol, patient drop-out and loss to follow-up,and use of quinolone antibiotics outside of the trial protocol.

Discussion: Results from this pilot study will provide vital information to design and conduct a large, multicenter trial to determine if quinolone therapy decreases clinically meaningful outcomes in kidney transplantation. If levofloxacin significantly reduces BK viruria and urine viral loads in kidney transplantation, it will provide important justification to progress to the larger trial. If the full trial shows that levofloxacin significantly reduces BK infection and improves outcomes, its use in kidney transplantation will be strongly endorsed given the lack of proven therapies for this condition.
\end{abstract}

Trial registration: This trial was funded by the Canadian Institutes of Health Research (grant number:222493) and is registered at ClinicalTrials.gov (NCT01353339).

Keywords: Kidney transplantation, BK virus, Polyomavirus, Quinolone, Levofloxacin, Randomized controlled trial

\footnotetext{
* Correspondence: gknoll@toh.on.ca

${ }^{\dagger}$ Equal contributors

${ }^{11}$ Department of Medicine, Ottawa Hospital Research Institute, University of

Ottawa, 1967 Riverside Drive, Ottawa, ON K1H 7W9, Canada

Full list of author information is available at the end of the article
} 


\section{Background}

Kidney transplantation is the treatment of choice for endstage renal disease as it prolongs survival [1], improves quality of life [2] and is less costly when compared to dialysis [3]. Acute rejection, once the major obstacle to successful kidney transplantation, has now been reduced to historically low levels (10\% in 2005 [4]). This major advancement in care, however, has been replaced by a new threat, BK virus infection. BK virus is a polyomavirus that occurs worldwide with a prevalence of 60 to $80 \%$ in the general population [5]. In kidney transplant recipients, immunosuppression leads to reactivation of the virus. BK virus replication progresses through specific stages: appearing first in the urine (BK viruria), then in the blood (BK viremia) and finally in the kidney transplant as an inflammatory nephritis (BK virus nephropathy) [6]. BK virus nephropathy generally has a poor prognosis with an average transplant failure rate of $46 \%$ but reaching as high as $100 \%$ in some series [7]. A recent series, however, has shown a more favourable prognosis [8]. In a cohort of patients with definitive BK virus nephropathy, 92\% had complete viral clearance with no graft losses at a median follow-up of 34 months [8].

Except for one study published in 1980 [9], there are no randomized controlled trials (RCTs) evaluating strategies to prevent or treat BK viruria, viremia or nephropathy. Based on uncontrolled data, experts $[6,10,11]$ and guidelines [5,7] have recommended that screening be adopted to detect $\mathrm{BK}$ viruria or viremia followed by a reduction in immunosuppression. Intuitively a good idea, this approach is problematic since many patients do not actually clear the virus with this strategy [12-14], immunosuppression reduction can lead to acute and chronic rejection [12,15], and, most importantly, long-term outcomes with this screening strategy remain uncertain [16].

We propose to conduct a RCT to determine if we can prevent $\mathrm{BK}$ virus infection from occurring rather than trying to treat the virus once replication has been established. Prophylactic strategies such as this are familiar to kidney transplant patients and physicians as they have become the standard of care for the prevention of Cytomegalovirus (CMV) [17] and Pneumocystis infection [18]. Quinolone antibiotics are safe, commonly used medications [19] that also have antiviral properties against BK virus $[20,21]$. We hypothesize that the administration of a quinolone, if given early post-transplantation, will prevent $B K$ viral replication in the urine and thus prevent systemic BK virus infection. Preliminary data in kidney transplant recipients have supported this preventive strategy.

\section{Methods/design}

This pilot study is a multicenter, double-blind, RCT comparing a 3-month course of the quinolone antibiotic, levofloxacin, to placebo in 154 kidney transplant recipients. This study has been approved by the Ottawa Hospital Research Ethics Board, Ottawa, ON, Canada (protocol number: 2010292-01H).

\section{Patient population}

The following patients are eligible for this trial: 1) primary or repeat kidney transplant recipients (deceased or living donor); and 2) adults $\geq 18$ years of age.

Exclusion criteria include: 1) patient unable to provide informed consent; 2) greater than 5 days posttransplantation; 3) BK virus nephropathy with a previous transplant; 4) history of allergic reaction to any quinolone antibiotic; 5) history of quinolone-associated tendonitis or tendon rupture; 6) corrected QT interval $\geq 450 \mathrm{~ms}$; 7) taking medication known to prolong the QT interval, such as class IA antiarrhythmic drugs (for example quinidine, procainamide, disopyramide), class III antiarrhythmic drugs (for example amiodarone, sotalol), azole antifungals (for example fluconazole) or macrolide antibiotics (for example erythromycin); 8) pregnant or breastfeeding, since the safety of levofloxacin in these settings is not established; 9) require quinolone antibiotic for $>14$ days (for example for UTI prophylaxis); 10) received a multiorgan transplant (for example kidney-pancreas); 11) currently enrolled in another interventional trial; 12) previously enrolled in this study; 13) history of rhabdomyolysis [22]; and 14) significant allergic reactions to $\geq 3$ classes of antibiotics, since these patients may have no other option other than quinolones for treatment of common posttransplant infection.

\section{Trial intervention}

The target dose of levofloxacin is $500 \mathrm{mg}$ daily for 3 months. With normal kidney function, a single $500 \mathrm{mg}$ tablet of levofloxacin will produce a maximal urinary drug concentration of $406 \mathrm{mg} / \mathrm{l}$ [23]. At a concentration of $250 \mu \mathrm{g} / \mathrm{ml}$, levofloxacin was shown to inhibit 3/8 BK virus isolates [20]. At a concentration of $500 \mu \mathrm{g} / \mathrm{ml}$, levofloxacin was able to inhibit the remaining 5/8 isolates [20]. Thus, we expect that the $500 \mathrm{mg}$ tablet of levofloxacin given daily will result in sufficient urinary drug concentration to inhibit BK virus replication. Since this is a proof of concept pilot trial there are no published data to guide the duration of therapy. Given that 80 to $85 \%$ of $\mathrm{BK}$ virus infections begin within the first 3 months post-transplantation, a 3-month course of levofloxacin should prevent the majority of infections $[24,25]$. While 2 to 4 weeks of therapy might be the most conservative approach with regards to safety, we believe this would be insufficient to effectively prevent BK virus infection. Similarly, a prolonged course of therapy (for example 6 to 9 months) might prevent more BK virus infections but would have the potential for more adverse events, such as the emergence of resistant organisms. 
Thus, the 3-month treatment period represents a balance between efficacy and safety appropriate for a pilot study.

Levofloxacin is administered orally once daily in the morning. The $500 \mathrm{mg}$ daily dose is given as two $250 \mathrm{mg}$ capsules to allow for dose reductions if required. At each study visit, creatinine clearance is estimated using the Cockcroft-Gault formula [26] and the dose of levofloxacin is adjusted based on Canadian guidelines [27]. The medication is started as soon as the patient is able to take oral medications but must be started within 5 days post-transplant [28] to ensure early viral replication is prevented. The levofloxacin has been re-encapsulated so that the placebo is identical in appearance to the study medication.

\section{Other trial maneuvers}

Outside of the primary trial intervention, the only major interventions that are being controlled are CMV and Pneumocystis jirovecii infection prophylaxis. All participants are receiving prophylaxis against CMV and Pneumocystis based on established guidelines [29,30]. Consistent with current clinical practice, patients with a significant unexplained and sustained increase in serum creatinine undergo transplant biopsy. A set protocol has been developed outlining when study medication must be stopped (for example significant Clostridiumdifficile-associated diarrhea, rash, tendonitis). Co-interventions that might influence BK infection, such as immunosuppressive medication use, are being thoroughly documented but not controlled. Although immunosuppressive strategies are somewhat variable between centers, mandating a strict immunosuppressive regimen would have limited site participation and generalizability of study findings. More importantly, all immunosuppressive medications have been associated with BK virus infection and the net state of immunosuppression appears more important than individual agents [6,31].

As per our eligibility criteria, the routine use of quinolones for bacterial prophylaxis (for example urinary tract infection (UTI)) is not permitted. The investigators have agreed to not use quinolones for empiric antibiotic therapy. If a quinolone is absolutely necessary, then investigators have this option for the safety of the patient. We expect this situation to be rare given the choices of antibiotics available (for example cephalosporins, amoxicillin/ clavulanic acid, nitrofurantoin). A set protocol has been developed to guide the sites on non-study use of quinolones. Once cultures are available, patients are switched to a non-quinolone regimen. If the infection is only quinolone-sensitive or the patient is intolerant/allergic to other antibiotics, then quinolone use (beyond 24 to 48 hours) is allowed. During this time, study medication (placebo or levofloxacin) is withheld. All non-study use of quinolones is being thoroughly documented.

\section{Protecting against bias}

Patients are randomized using a web-based system. A permuted blocked randomization method stratified by center is used to allocate patients. An independent statistician has generated the randomization scheme. The randomization process consists of a computer-generated random listing of the treatment allocations stratified by center in variable permuted blocks of 2 and 4. Only the independent statistician and designated research pharmacist at the coordinating center has knowledge of the randomization codes to ensure concealed randomization of the patients. After screening the patient for eligibility and obtaining informed consent, the study coordinator accesses the trial website and provides the subject's unique identification, as well as a confirmation of consent and eligibility. The website returns the next available randomization number.

In order to minimize selection and ascertainment biases, physicians, nurses, investigators and research staff are blinded to the randomization schemes and treatments administered. The study medication and placebo are identical in appearance. The designated research pharmacist at the coordinating center is expressly forbidden to discuss individual treatment allocation with the study team or any patients. In addition, the staff at the central laboratory performing the BK virus measurements are not aware of the patient's treatment allocation. Given that this trial is blinded, contamination and cointerventions should not become imbalanced between the treatment arms. We are documenting the use of cointerventions that may have some impact on BK virus, such as immunosuppressive drug selection, dose and levels [6], leflunomide [6,32], cidofovir [6,33], and intravenous immunoglobulin $[6,34]$.

\section{Participant follow-up}

Patients are being followed for 1 year after the time of randomization. Study visits take place every 4 weeks for the first 24 weeks, then at 32, 40 and 52 weeks. A 1-year follow-up should be sufficient since only 1.0 to $1.3 \%$ of patients develop viremia and only $3 \%$ develop viruria beyond 40 weeks post-transplantation $[24,35]$.

\section{Outcome measures}

The primary outcome of the pilot study is the time to occurrence of BK viruria within the first year posttransplantation [36]. BK viruria is defined as $\geq 500$ copies/ $\mathrm{ml}$ of BK virus DNA in the urine, which corresponds to the lower limit of detection for our BK virus assay for urine samples. BK virus infection is determined at each study visit (baseline; every 4 weeks for the first 24 weeks; 
then at 32, 40 and 52 weeks) by testing for BK viral DNA in urine samples. We have established methods to perform quantitative real-time PCR (qPCR) for the detection of $\mathrm{BK}$ virus at our central laboratory at the University of Alberta, Edmonton, AB, Canada. The assay we are using has been in clinical use for the provincial kidney transplant programs and has been used as a reference assay for clinical trials, including one funded by the National Institutes of Health (NIH), Bethesda, MD, USA. Detailed performance characteristics of the assay have been published [37].

Secondary safety outcomes include: 1 ) incidence and type of all adverse events; 2) incidence of acute rejection; 3 ) incidence of microbiologically confirmed $C$ difficile-associated diarrhea; 4) incidence of other infections (viral, bacterial, fungal) based on established guidelines; 5) incidence of quinolone resistance where a quinolone would have been a therapeutic option (for example Escherichia coli UTI); 6) effect of levofloxacin on immunosuppressive drug doses and blood levels [38-40]; and 7) transplant failure and mortality.

Secondary feasibility outcomes include: 1) number of patients transplanted during the recruitment period who are randomized into the trial; 2) proportion of randomized participants who are adherent to the protocol. Participants who take at least $80 \%$ of study medication and do not report any episodes of non-adherence will be classified as adherent. Medication use will be measured by pill count at each study visit. In addition, the participants will be questioned about any missed doses. Based on data from the literature [41-44] and the fact that our trial involves 3 months of therapy, we will judge this outcome to be successful if $>75 \%$ of participants are adherent; 3 ) use of quinolones outside of the protocol; and 4)proportion of patient drop-out and loss to follow-up.

Secondary clinical outcomes include quantitative BK viral load in urine and the time to occurrence of BK viremia (defined as $\geq 25$ copies/ml of $\mathrm{BK}$ virus DNA in the plasma).

\section{Sample size}

Based on data from the literature, we estimate that 35\% of patients in the placebo group will develop BK viruria by 1-year post-transplantation [24]. In order to detect an absolute reduction in $\mathrm{BK}$ viruria of $20 \%$ (from 35 to $15 \%$ ) with a two-sided alpha error of 0.05 , a beta error of 0.2 and a $5 \%$ loss to follow-up rate, we would need 154 patients in total (77 per group). The minimal clinically important difference of $20 \%$ was justified based on a survey of experts from the Canadian Renal Transplant Study Group. The investigators wanted to see a substantial effect on viruria in order to justify proceeding with a larger trial examining the more clinically relevant endpoint of time to doubling serum creatinine, transplant failure or death.

\section{Statistical analysis}

Baseline characteristics of patients in the two treatment arms will be assessed using frequency distributions and univariate descriptive statistics, including measures of central tendency and dispersion. Analyses will be performed by intention-to-treat. Since this is a pilot study to assess biologic efficacy, the intention-to-treat analysis will be supplemented by a sensitivity analysis that excludes patients who did not complete the allocated treatment plan. The primary analysis will use a nonparametric log-rank test, stratified by center, to compare the time to occurrence of $\mathrm{BK}$ viruria between the control and levofloxacin treatment groups. Kaplan-Meier survival curves will also be plotted to visually assess differences in incidence over time.

For secondary safety outcomes, the proportion of adverse events occurring in each treatment arm will be compared using an unadjusted chi-square test or Fisher's exact test if cell sizes are small. We will evaluate overall adverse events as well as specific serious adverse events (for example $C$ difficile-associated diarrhea). For the secondary feasibility outcome of recruitment, we will calculate the proportion (and 95\% confidence interval) of all patients transplanted during the recruitment period who are randomized into the trial. In addition, we will calculate the proportion of patients that are eligible but consent declined, eligible but not approached and not eligible. These analyses will be performed at each site and for the trial overall. For the secondary feasibility outcomes of adherence, non-study quinolone use, drop-out and loss to follow-up, the proportion of each outcome will be compared between the arms with an unadjusted chi-square or Fisher's exact test. Since this is a pilot study, we have not planned for any formal interim analyses.

\section{Discussion}

BK virus infection has emerged as a major complication in kidney transplantation. There are no proven strategies to prevent or treat $\mathrm{BK}$ virus infection. This trial will assess the efficacy, safety and feasibility of a 3-month course of levofloxacin to prevent BK virus infection following kidney transplantation. While there are concerns about possible antimicrobial resistance and complications, such as $C$ difficile-associated diarrhea, we are closely monitoring safety and adverse events as part of this trial. Results from this pilot study will provide vital information to design and conduct a large, multicenter trial to determine if levofloxacin therapy decreases major clinical outcomes, such as biopsy-proven BK nephropathy or graft loss in kidney transplantation. If levofloxacin significantly reduces BK viruria and urine viral loads in kidney transplantation, it will provide strong support of biologic effect and justification to progress to the larger trial. If the full trial shows that levofloxacin significantly 
reduces $\mathrm{BK}$ infection and improves outcomes, the use of this preventive therapy will be a major innovation in the management of kidney transplant recipients, especially given the lack of proven therapies for this condition.

\section{Trial status}

The first participant was randomized in December 2011 and recruitment is ongoing as of 28 May 2013.

\section{Abbreviations}

CMV: Cytomegalovirus; NIH: National Institutes of Health; PCR: Polymerase chain reaction; qPCR: Quantitative real-time PCR; RCT: Randomized controlled trial; UTI: Urinary tract infection.

\section{Competing interests}

The authors declare that they have no competing interests related to this study.

\section{Authors' contributions}

$\mathrm{AH}, \mathrm{JG}$ and GAK conceived the study, participated in its design and submission to the Canadian Institutes of Health Research for funding, and drafted the manuscript. DF, AH, SC, MC, MK and TR participated in the design of the study and submission to the Canadian Institutes of Health Research for funding. OJ, SJK, LL and JZ contributed to the design of the study. All authors read and approved the final manuscript.

\section{Author details}

'Department of Medicine, Faculty of Medicine \& Dentistry, 2J2.00 WC Mackenzie Health Sciences Centre, University of Alberta, Edmonton, AB T6G 2R7, Canada. ${ }^{2}$ Department of Medicine, St Paul's Hospital, 1081 Burrard Street, Vancouver, BC V6Z 1Y6, Canada. ${ }^{3}$ Department of Medicine, Vancouver General Hospital, 855 West 12th Avenue, Vancouver, BC V5Z 1M9, Canada. ${ }^{4}$ Clinical Epidemiology Program, Ottawa Hospital Research Institute, 501 Smyth Road, Ottawa, ON K1H 8L6, Canada. ${ }^{5}$ Department of Medicine, Western University and London Health Sciences Centre, 339 Windermere Road, London, ON N6A 5A5, Canada. ${ }^{6}$ Clinical Epidemiology Program, Ottawa Hospital Research Institute, 501 Smyth Road, Ottawa, ON K1H 8L6, Canada. ${ }^{7}$ Department of Medicine, Toronto General Hospital, 200 Elizabeth Street, Toronto, ON M5G 2C4, Canada. ${ }^{8}$ Department of Medicine, St Michael's Hospital, 30 Bond Street, Toronto, ON M5B 1W8, Canada. ${ }^{9}$ Department of Medicine, McGill University Health Center, 687 Pine Avenue West, Montreal, QC H3A 1A1, Canada. ${ }^{10}$ Department of Medicine, University of Manitoba, 820 Sherbrook Street, Winnipeg, MB R3T 2N2, Canada. " ${ }^{11}$ Department of Medicine, Ottawa Hospital Research Institute, University of Ottawa, 1967 Riverside Drive, Ottawa, ON K1H 7W9, Canada.

Received: 2 April 2013 Accepted: 6 June 2013

Published: 21 June 2013

\section{References}

1. Wolfe RA, Ashby VB, Milford EL, Ojo AO, Ettenger RE, Agodoa LY, Held P, Port F: Comparison of mortality in all patients on dialysis, patients on dialysis awaiting transplantation, and recipients of a first cadaveric transplant. N Engl J Med 1999, 341:1725-1730.

2. Russell JD, Beecroft M, Ludwin D, Churchill DN: The quality of life in renal transplantation-a prospective study. Transplantation 1992, 54:656-660.

3. Laupacis A, Keown P, Pus N, Krueger H, Ferguson B, Wong C, Muirhead N: A study of the quality of life and cost-utility of renal transplantation. Kidney Int 1996, 50:235-242.

4. Healthcare Systems Bureau, Division of Transplantation: 2007 Annual Report of the US Organ Procurement and Transplantation Network and the Scientific Registry of Transplant Recipients: Transplant Data 1997-2006. Rockville, MD: Health Resources and Services Administration; 2008.

5. BK virus. Am J Transplant 2004, 4(Suppl 10):89-91.

6. Bohl DL, Brennan DC: BK virus nephropathy and kidney transplantation. Clin J Am Soc Nephrol 2007, 2(Suppl 1):36-46.

7. Hirsch HH, Brennan DC, Drachenberg CB, Ginevri F, Gordon J, Limaye AP, Mihatsch MJ, Nickeleit V, Ramos E, Randhawa P, Shapiro R, Steiger J, Suthanthiran M, Trofe J: Polyomavirus-associated nephropathy in renal transplantation: interdisciplinary analyses and recommendations. Transplantation 2005, 79:1277-1286.

8. Schaub S, Hirsch HH, Dickenmann M, Steiger J, Mihatsch MJ, Hopfer H, Mayr M: Reducing immunosuppression preserves allograft function in presumptive and definitive polyomavirus-associated nephropathy. Am J Transplant 2010, 10:2615-2623.

9. Cheeseman SH, Black PH, Rubin RH, Cantell K, Hirsch MS: Interferon and BK Papovavirus-clinical and laboratory studies. J Infect Dis 1980, 141:157-161.

10. Hariharan S: BK virus nephritis after renal transplantation. Kidney Int 2006, 69:655-662.

11. Randhawa $P$, Brennan $D C: B K$ virus infection in transplant recipients: an overview and update. Am J Transplant 2006, 6:2000-2005.

12. Almeras C, Foulongne V, Garrigue V, Szwarc I, Vetromile F, Segondy M: Does reduction in immunosuppression in viremic patients prevent $B K$ virus nephropathy in de novo renal transplant recipients? A prospective study. Transplantation 2008, 85:1099-1104.

13. De Paolis $\mathrm{P}$, Gervasio E, Tedesco M, Favaro A, lappelli M, Abbate I, Capobianchi M, Di Giulio S: Impact of preemptive reduction of immunosuppression with serial monitoring for BK virus replication in renal transplant recipients undergoing short-term evaluation. Transplant Proc 2009, 41:1207-1209.

14. Hymes $L C$, Warshaw BL: Polyomavirus (BK) in pediatric renal transplants: evaluation of viremic patients with and without BK associated nephritis. Pediatr Transplant 2006, 10:920-922.

15. Ryan J, Zanabli A, Cosio FG, Stegall MD, Larson TS, Griffin M: Outcomes of immunosuppression reduction in BK viremic kidney transplant recipients screened at 4 months post-transplant. Am J Transplant 2007, 7(Suppl 2):537.

16. Hardinger K, Koch M, Bohl D, Storch G, Brennan D: BK-Virus and the Impact of Pre-Emptive Immunosuppression Reduction: 5-Year Results. Am J Transplant 2010, 10:407-415.

17. Preiksaitis JK, Brennan DC, Fishman J, Allen U: Canadian society of transplantation consensus workshop on cytomegalovirus management in solid organ transplantation final report. Am J Transplant 2005, 5:218-227.

18. (2004), Pneumocystis jiroveci (formerly Pneumocystis carinii). Am J Transplant, 4:135-141. doi:10.1111/j.1600-6135.2004.00736.x

19. Owens RC Jr, Ambrose PG: Antimicrobial safety: focus on fluoroquinolones. Clin Infect Dis 2005, 41(Suppl 2):S144-S157.

20. Leung AY, Chan MT, Yuen KY, Cheng VC, Chan KH, Wong CL, Liang R, Lie AK, Kwong YL: Ciprofloxacin decreased polyoma BK virus load in patients who underwent allogeneic hematopoietic stem cell transplantation. Clin Infect Dis 2005, 40:528-537.

21. Ali SH, Chandraker A, DeCaprio JA: Inhibition of Simian virus 40 large T antigen helicase activity by fluoroquinolones. Antivir Ther 2007, 12:1-6.

22. Korzets A, Gafter U, Dicker D, Herman M, Ori Y: Levofloxacin and rhabdomyolysis in a renal transplant patient. Nephrol Dial Transplant 2006, 21:3304-3305

23. Wagenlehner FM, Kinzig-Schippers M, Sorgel F, Weidner W, Naber KG Concentrations in plasma, urinary excretion and bactericidal activity of levofloxacin $(500 \mathrm{mg})$ versus ciprofloxacin $(500 \mathrm{mg})$ in healthy volunteers receiving a single oral dose. Int I Antimicrob Agents 2006, 28:551-559.

24. Brennan DC, Agha I, Bohl DL, Schnitzler MA, Hardinger KL, Lockwood M, Torrence S, Schuessler R, Roby T, Gaudreault-Keener M, Storch GA: Incidence of BK with tacrolimus versus cyclosporine and impact of preemptive immunosuppression reduction. Am J Transplant 2005, 5:582-594.

25. Bressollette-Bodin C, Coste-Burel M, Hourmant M, Sebille V, Andre-Garnier E, Imbert-Marcille BM: A prospective longitudinal study of BK virus infection in 104 renal transplant recipients. Am J Transplant 2005, 5:1926-1933.

26. Gault MH, Longerich LL, Harnett JD, Wesolowski C: Predicting glomerular function from adjusted serum creatinine. Nephron 1992, 62:249-256.

27. Repchinsky C: Compendium of Pharmaceuticals and Specialties. Ottawa: Canadian Pharmacists Association; 2007.

28. Paya C, Humar A, Dominguez E, Washburn K, Blumberg E, Alexander B, Freeman R, Heaton N, Pescovitz MD: Efficacy and safety of valganciclovir vs. oral ganciclovir for prevention of cytomegalovirus disease in solid organ transplant recipients. Am J Transplant 2004, 4:611-620.

29. Humar A, Snydman D: Cytomegalovirus in solid organ transplant recipients. Am J Transplant 2009, 9(Suppl 4):S78-S86. 
30. Martin SI, Fishman JA: Pneumocystis pneumonia in solid organ transplant recipients. Am J Transplant 2009, 9(Suppl 4):S227-S233.

31. Hirsch HH, Drachenberg CB, Steiger J, Ramos E: Polyomavirus-associated nephropathy in renal transplantation: critical issues of screening and management. Adv Exp Med Biol 2006, 577:160-173.

32. Josephson MA, Gillen D, Javaid B, Kadambi P, Meehan S, Foster P, Harland R, Thistlethwaite RJ, Garfinkel M, Atwood W, Jordan J, Sadhu M, Millis MJ, Williams J: Treatment of renal allograft polyoma BK virus infection with leflunomide. Transplantation 2006, 81:704-710.

33. Kuypers DRJ, Vandooren AK, Lerut E, Evenepoel P, Claes K, Snoeck R, Naesens L, Vanrenterghem Y: Adjuvant low-dose cidofovir therapy for BK polyomavirus interstitial nephritis in renal transplant recipients. Am J Transplant 2005, 5:1997-2004

34. Sener A, House AA, Jevnikar AM, Boudville N, McAlister VC, Muirhead N: Intravenous immunoglobulin as a treatment for BK virus associated nephropathy: one-year follow-up of renal allograft recipients. Transplantation 2006, 81:117-120.

35. Hirsch HH, Knowles W, Dickenmann M, Passweg J, Klimkait T, Mihatsch MJ, Steiger J: Prospective study of polyomavirus type BK replication and nephropathy in renal-transplant recipients. N Engl J Med 2002, 347:488-496.

36. Humar A, Michaels M: American society of transplantation recommendations for screening, monitoring and reporting of infectious complications in immunosuppression trials in recipients of organ transplantation. Am J Transplant 2006, 6:262-274.

37. Pang XL, Doucette K, LeBlanc B, Cockfield SM, Preiksaitis JK: Monitoring of polyomavirus $B K$ virus viruria and viremia in renal allograft recipients by use of a quantitative real-time PCR assay: one-year prospective study. J Clin Microbiol 2007, 45:3568-3573.

38. Federico S, Carrano R, Capone D, Gentile A, Palmiero G, Basile V: Pharmacokinetic interaction between levofloxacin and ciclosporin or tacrolimus in kidney transplant recipients: ciclosporin, tacrolimus and levofloxacin in renal transplantation. Clin Pharmacokinet 2006, 45:169-175.

39. Wrishko RE, Levine M, Primmett DR, Kim S, Partovi N, Lewis S: Investigation of a possible interaction between ciprofloxacin and cyclosporine in renal transplant patients. Transplantation 1997, 64:996-999.

40. Borrows R, Chusney G, Loucaidou M, James A, Van Tromp J, Cairns T: The magnitude and time course of changes in mycophenolic acid 12-hour predose levels during antibiotic therapy in mycophenolatemofetil-based renal transplantation. Ther Drug Monit 2007, 29:122-126.

41. Moyses NM, Costa RS, Reis MA, Ferraz AS, Saber LT, Batista ME: Use of ciprofloxacin as a prophylactic agent in urinary tract infections in renal transplant recipients. Clin Transplant 1997, 11:446-452.

42. Hibberd PL, Tolkoff-Rubin NE, Doran M, Delvecchio A, Cosimi AB, Delmonico FL, Auchincloss H Jr, Rubin RH: Trimethoprim-sulfamethoxazole compared with ciprofloxacin for the prevention of urinary tract infection in renal transplant recipients. A double-blind, randomized controlled trial. Online J Curr Clin Trials 1992. Doc No 15.

43. Nickel JC, Downey J, Clark J, Casey RW, Pommerville PJ, Barkin J: Levofloxacin for chronic prostatitis/chronic pelvic pain syndrome in men: a randomized placebo-controlled multicenter trial. Urology 2003, 62:614-617.

44. Bundrick W, Heron SP, Ray P, Schiff WM, Tennenberg AM, Wiesinger BA: Levofloxacin versus ciprofloxacin in the treatment of chronic bacterial prostatitis: a randomized double-blind multicenter study. Urology 2003, 62:537-541.

doi:10.1186/1745-6215-14-185

Cite this article as: Humar et al.: Quinolone prophylaxis for the prevention of BK virus infection in kidney transplantation: study protocol for a randomized controlled trial. Trials 2013 14:185.

\section{Submit your next manuscript to BioMed Central and take full advantage of:}

- Convenient online submission

- Thorough peer review

- No space constraints or color figure charges

- Immediate publication on acceptance

- Inclusion in PubMed, CAS, Scopus and Google Scholar

- Research which is freely available for redistribution

Submit your manuscript at www.biomedcentral.com/submit
C Biomed Central 